\title{
Triangular Dislocation Loop Model for Surface Displacement in Indented Thin Films
}

\author{
Shinji Muraishi ${ }^{a}$, Hiromitsu Chinen ${ }^{b}$, Masaaki Takaya ${ }^{c}$, Kousuke Hara $^{d}$ \\ Metallurgy and Ceramics Science, Tokyo Institute of Technology, 2-12-1 Ookayama, Meguro-ku \\ Tokyo 152-8552, Japan \\ ${ }^{a}$ muraishi.s.aa@m.titech.ac.jp, ${ }^{b}$ Chinen.h.aa@m.titech.ac.jp, ${ }^{c}$ takaya.m.aa@m.titech.ac.jp, \\ hara.k.aa@m.titech.ac.jp
}

Keywords: Indentation, dislocation, TEM, AFM

\begin{abstract}
The surface displacement of the indented layered composite has been observed by AFM and TEM, and the elastic recovery due to the indentation residual stress is compared with the prediction of the triangular dislocation model. At the shoulders of the indentation, the upheaval of $\mathrm{Al}-4 \mathrm{wt} \% \mathrm{Cu}$ film is smoothly connected, whereas that of $\mathrm{Al}_{2} \mathrm{Cu}$ film is localized as the intensive sheared displacement. The magnitude of the elastic recovery in film/substrate composite is larger than the predicted value, which might be attributed to the repulsive interaction between the glide dislocations and the hard Si substrate.
\end{abstract}

\section{Introduction}

The depth sencing indentation method is frequently used for the measurement of Young's modulus and Hardness in film/substrate composite [1]. However, since the contact area is estimated from the indentation depth, the surface upheavals at the trace of indentation bring significant error for the derivation of the actual contact area. The surface upheavals around the contact surface is regarded as the backward displacement due to the indentation residual stress, which is attributed to the plastic deformation beneath the indentation tip.

In view of the dislocation theory, the elastic/plastic boundary of the indentation plastic domain is represented by the geometrycally nesecity dislocations, where the indentation plastic displacement is given by the sum of Burgers vector, whereas the elastic recovery is represented by the elastic field of the dislocation arrays. In the literature [2,3], the indentation residual stress has been investigated by the elastic field of prismatic dislocation loops. The applied pressure needed for Vickers indentation was investigated by Tanaka [3], where the elastic recovery associated with the circular prismatic loop arrays were numerically solved by summing an analytical solution for a single prismatic loop field in two phase material [4]. The square dislocation loop model for Vickers indentation was presented by Mura [3]. Comparing with the circular loop model, the displacement values at the edge and the corner can be calculated since the trace of prismatic loop arrays is consisent with the ideal shape of an indenter. In addition, according to Mura's superposition method, indenter tips of any shape can be modeled by a simple arrangement of dislocation segments.

In the present study, the elastic recovery due to the triangular dislocation loops has been calculated, and made a comparison with the measurement of trans mission electron microscopy (TEM) and atomic force microscopy (AFM).

\section{Experimental Procedures}

The deposition of $\mathrm{Al}-4 \mathrm{wt} \% \mathrm{Cu}$ and $\mathrm{Al}_{2} \mathrm{Cu}$ films on $\mathrm{Si}$ substrate has been performed by ion beam sputtering method, where the chemical composition of the $\mathrm{Al}_{2} \mathrm{Cu}$ film was controlled by the certain area fraction of pure $\mathrm{Al}$ and $\mathrm{Cu}$ plates. The depth sensing indentation experiments has been performed by DUH-201 (Shimazu), and the maximum load of $50[\mathrm{mN}]$ was applied so that the penetration depth would correspond to the film thickness. The surface profiles of indented film were observed by AFM (Veeco). The cross section of the indented microstructure of film/substrate composite has been observed by TEM (JEM3010: JEOL). For TEM sample preparation, cross section of the composite 
was mechanically cut and polished to $50[\mu \mathrm{m}]$ in thick, and then focused ion beam method was conducted. The theoretical indentation displacement of triangular dislocation model was calculated by Mathmatica 5.4. The detail of polygonal dislocation loop is mentioned elsewhere [5]

\section{Results and Discussion}

Theoretical Indentation Recovery of Triangular Loop Model. The total displacements by the indentation is described by the plastic displacement due to the Burgers vectors and their elastic displacement as follows.

$$
\mathbf{u}_{3}^{\mathrm{t}}=\mathbf{u}_{3}^{\mathrm{e}}+\mathbf{u}_{3}^{\mathrm{b}}
$$

Assuming that the prismatic dislocation loop with Burgers vector, $\mathbf{b}_{3}$, normal to the free surface is introduced beneath the contact surface, the maximum indentation depth, $h_{p}$, at the loop center is given by the total number of the dislocation loops, $\mathrm{N}$, as follows.

$$
\mathbf{h}_{p}=\mathrm{Nb}_{3}
$$

The elastic recovery due to the indentation residual stress is calculated by the superposition of the triangular dislocation loops at the hemispherical boundary as shown in Fig. 1. Numbers of triangular loop is set as $\mathrm{N}=100$, which is sufficient to express the smooth boundary of plastic domain. Vertical displacement, $\mathrm{u}_{3}$, and the axes of the loop field is normalized by the indentation depth, $\mathrm{h}_{\mathrm{p}}$, and the distance between the edge and the center of the indenter, $\mathrm{c}_{\mathrm{p}}$, respectively. The detaile of the elatic recovery is mentioned elsewhere [5].

At the center of the indentation $\left(\mathrm{u}_{3} / \mathrm{h}_{\mathrm{p}}=1\right)$, the elastic recovery amounts to $46.6 \%$ in maximum. On the edge of the indented surface, the elastic recovery is $2.3 \%$ at the corner of the triangle $\left(\mathrm{x}_{2} / \mathrm{c}_{\mathrm{p}}=\right.$ $-2.0), 14.5 \%$ at the middle of the triangular segment $\left(\mathrm{x}_{2} / \mathrm{c}_{\mathrm{p}}=1.0\right)$. It should be noted that, the glide distance of dislocations doesn't change the plastic portion of the displacement, whereas the magnitude of the elastic recovery would vary with the dislocation arrangement because the interaction force is inversely proportional to the distance between the interface and the dislocations. Accounting for that the irreversal plastic work done by the external load should be consistent with that done by the dislocations, the volume of the plastic domain should be smaller when the repulsive interaction acting on the moving dislocation to diminish the travelling distance of the dislocations. The effect of the dislocation arrangement or the plastic domain shape on the elastic recovery is mentioned elsewhere [5].

a)

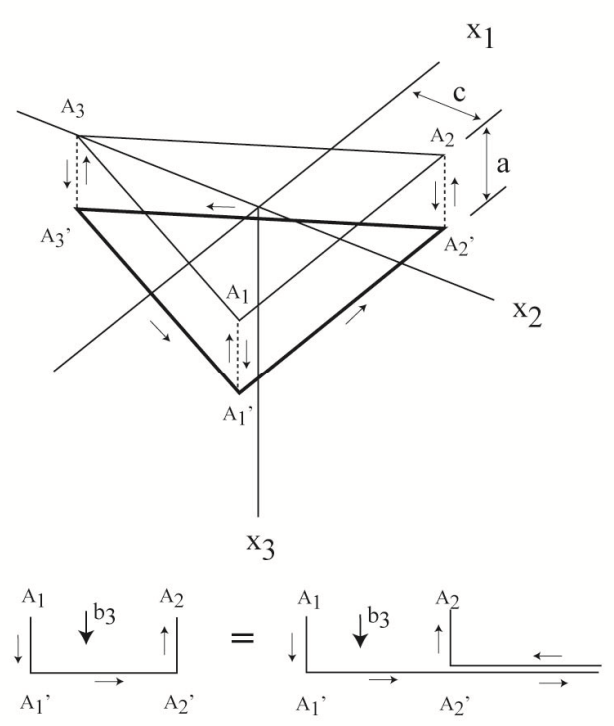

b)

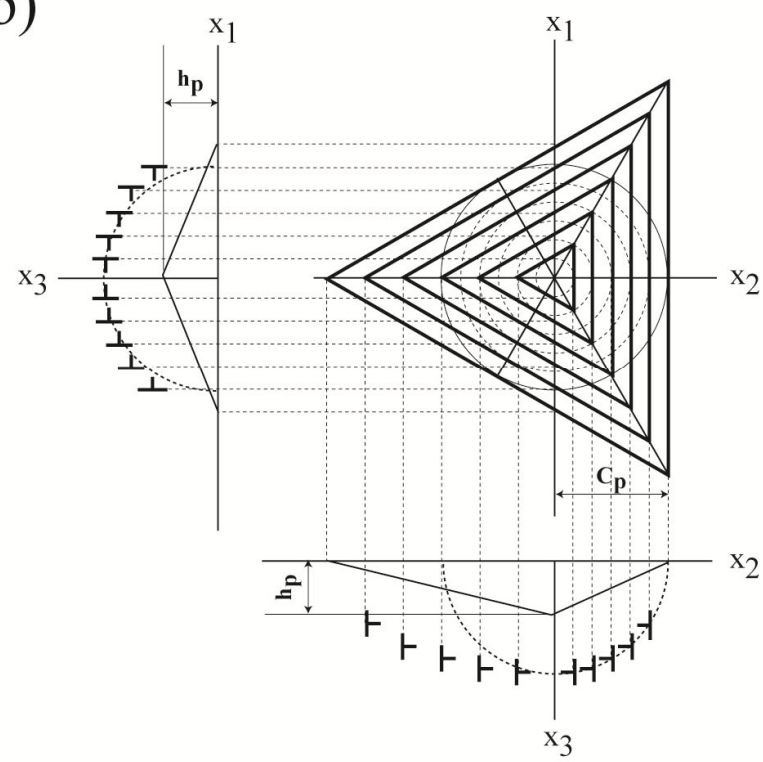

Figure 1 Triangular dislocation model in infinite half space. 


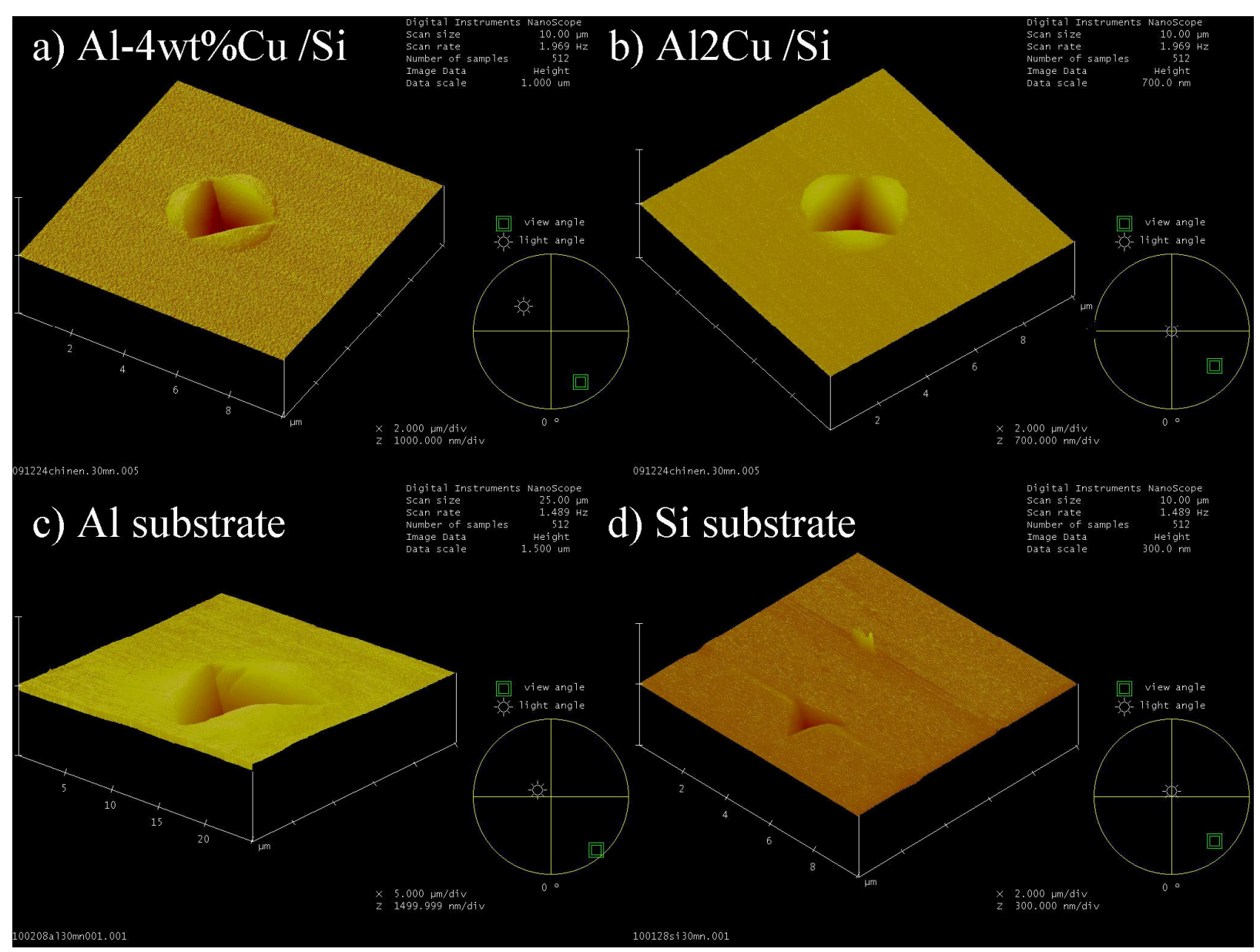

Figure 2 The AFM images of indented $\mathrm{Al}-4 \mathrm{wt} \% \mathrm{Cu}$ film (a), $\mathrm{Al}_{2} \mathrm{Cu}$ film (b), $\mathrm{Al}$ plate (c) and $\mathrm{Si}$ substrate(d). The upheaval of the film/Si substrateare shows higher amounts of elastic recovery as compared with Al sheet and Si substrate.

Observation of Surface Upheavals on Indented Films. AFM observation has been conducted for indented $\mathrm{Al}-4 \mathrm{wt} \% \mathrm{Cu}, \mathrm{Al}_{2} \mathrm{Cu}$ films on $\mathrm{Si}$ substrate. The scanning images are represented in Figs. 2 (a) and (b). For the comparison study, the indentation surface profiles of Al plate with the thickness of $1[\mathrm{~mm}]$ and Si substrate are represented in (c) and (d). The indentation maximum load is 30 [mN].

As comparing the surface profiles of the films with the thick Al plate, the upheavals of the films in (a) and (b) are clearly observed and localized at the trace of the indentation. The recovery ratio, $\mathrm{u}_{3} / \mathrm{h}_{\mathrm{p}}$, at the middle of the triangular segment amounts to 25 to 35 [\%] for $\mathrm{Al}-4 \mathrm{wt} \% \mathrm{Cu}$ and $\mathrm{Al}_{2} \mathrm{Cu}$ films, in contrast to that, the elastic recovery for Al plate amounts to 15 [\%] in (c).

Accounting for the irreversal work done by the indentation, Al plate suffers the larger indentation plastic displacement as compared with the films/substrate composites at the same applied load, so that elastic portion of the external work decreases as a consequence. The elastic displacement, $h_{e}$, is derived from the ralation between the work done by external load, $\mathrm{P}$, and the irreversal work done by the dislocation, $\mathrm{W}^{\mathrm{dis}}$, as follows,

$$
\mathrm{U} \equiv \int \mathrm{Pdh}-\mathrm{W}^{\mathrm{dis} \cong} \cong \frac{\mathrm{p}}{2} \mathrm{~h}_{\mathrm{p}}-\mathrm{W}^{\mathrm{dis}}=\frac{\mathrm{p}}{2} \mathrm{~h}_{\mathrm{a}}
$$

The cross-sectional TEM microstructure of indented $\mathrm{Al}-4 \mathrm{wt} \% \mathrm{Cu}$ and $\mathrm{Al}_{2} \mathrm{Cu}$ films are represented in Figs. 3. The indentation load is $50[\mathrm{mN}]$ in maximun. The upheaval at the shoulder of the indentation is smoothly connected of $\mathrm{Al}-4 \mathrm{wt} \% \mathrm{Cu}$ film (a), whereas that of $\mathrm{Al}_{2} \mathrm{Cu}$ film shows discontinuous stepped displacements. Judging from the slope of the inclined columnar grains, degree of the plastic deformation is significant at the center of the indentation and gradually decreases toward the edge of indentation as represented in (a). However, since the evidence of the plastic deformation is hardry observed in Si substrate, larger elastic recovery is suggested for the film substrate composite as discussed in AFM results. The different morphology of the upheaved surface 
implies that the annihilation of the internal stress is necesally at the bonded interface with $\mathrm{Si}$ and its process depneds on the plasticity of the indented material because the tractions and displacements should be conserved for the hard Si substrate.
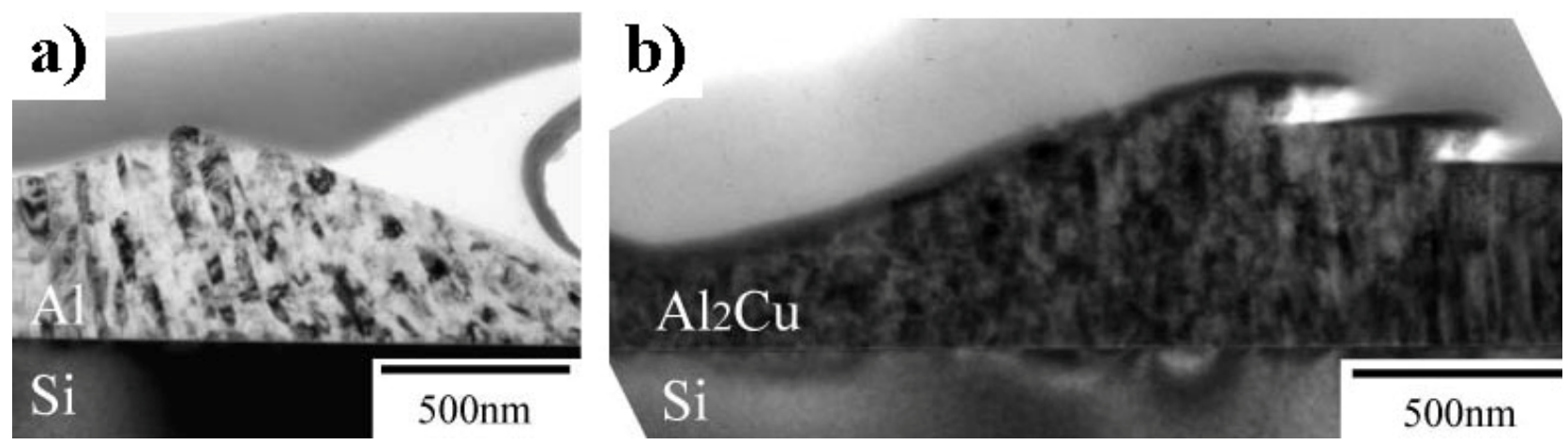

Figure 3 Cross-section views of indented $\mathrm{Al}-4 \mathrm{wt} \% \mathrm{Cu}$ film (a), $\mathrm{Al} 2 \mathrm{Cu}$ film (b)

\section{Summary}

The surface displacement of indented film/substrate composite has been investigated by AFM and TEM, and compared with the theoretical elastic recovery by triangular dislocation model. The upheaval at the indentation shoulders of $\mathrm{Al}$ and $\mathrm{Al}_{2} \mathrm{Cu}$ films is about 25 35 [\%], whereas $\mathrm{Al}$ plate shows $15[\%]$ at the middle of the triangular segments. Accounting for the theoretical elastic recovery of the triangular dislocation model, the large elastic recovery observed in the film/substrate composite might be responsible for that the repulsive interaction acting on the glide dislocations decrease the irreversible plastic work done by the dislocations, as a consequence, the amount of potential work is conserved.

\section{References}

[1] S.Muraishi,Thin Solid Films Vol.518 (2009), p. 233

[2] T. Mura, N. Yamashita, T. Mishima and Y. Hirose, Int. J. Engng. Sci. Vol.1 (1989), p. 1

[3] K.Tanaka, H. Koguchi and T. Mura, Int.J.Engng.Sci. Vol.1 (1989), p. 11

[4] N.J.Salamon and J.Dundurs, Journal of Elasticity Vol.1 (1971), p. 153

[5] S.Muraishi: submitted to Acta Materialia (2010) 